\title{
Sistem Informasi Data Beras Pada Kantor Perum Bulog Sub Divre Wilayah I Ternate
}

\author{
Kasmawati $^{1}$, Sitna Hajar Hadad ${ }^{2}$, Abjan Samad ${ }^{3}$ \\ Program Studi Manajemen Informatika \\ Akademi Ilmu Komputer Ternate \\ kasmawati13@gmail.com
}

\begin{abstract}
Abstrak
Seiring dengan perkembangan teknologi infomasi saat ini dilihat dari perkembangan teknologi informasi yang sangat pesat telah merambat penggunaanya diberbagi sektor baik digunakan untuk sektor perdagangan,maupun pemberian pelayanaan publik. Perum BULOG merupakan salah satu perusahaan BUMN yang bergerak di bidang logistik beras dan ketahanan pangan. Sebagai perusahaan yang tetap mengemban tugas publik dari pemerintah, BULOG dalam melakukan kegiatan yang dapat melakukan kestabilan harga dasar pembelian untuk gabah, stabilisasi harga khususnya harga pokok, menyalurkan beras untuk orang miskin (Raskin) dan pengelolaan stok pangan. Perum Bulog Sub Divre Wilayah I Ternate masih menggunakan Microsoft excel sehingga masih kurang ofisien, cepat dan tepat dalam pengolahan data beras. Dengan melihat kekurangan pengolahan data tersebut, maka dibutuhkan sebuah sistem baru yang mampu melakukan pengolahan data secara cepat dan akurat. Salah satu bentuk pengolahan informasi berbasis komputerisasi yaitu sebuah sistem yang memanfaatkan aplikasi web dengan menggunakan pemrograman $P H P$ dan $M y S Q L$ sebagai basis datanya sehingga memberi kemudahan serta kecepatan pengiriman, penyampaian dan penerimaan informasi bagi pengguna.
\end{abstract}

Kata Kunci: Sistem Informasi, BULOG, PHP, MySQL

\begin{abstract}
Along with the development of information technology today seen from the development of information technology that has been very rapid has spread its use in various sectors, both used for the trade sector, as well as providing public services. Public Corporation Bulog is a state-owned company engaged in rice logistics and food security. As a company that continues to carry out general duties from the government, BULOG in carrying out activities that can stabilize the basic purchase price for grain, stabilize prices especially basic prices, distribute rice to the poor (Raskin) and manage food stocks. Perum Bulog Sub Divre Region I Ternate still uses Microsoft Excel so it is even less efficient, fast, and precise in processing rice data. By looking at the lack of data processing, we need a new system that can do data processing quickly and accurately. One form of computerized based information processing is a system that utilizes web applications using PHP and MySQL programming as a database to provide convenience and speed of sending, delivering and receiving information for users.
\end{abstract}

Keywords: Information Systems, BULOG, PHP, MySQL 
PENDAHULUAN

Seiring dengan perkembangan teknologi infomasi saat ini dilihat dari perkembangan teknologi informasi yang sangat pesat telah merambat penggunaanya diberbagi sektor baik digunakan untuk sektor perdagangan,maupun pemberian pelayanaan publik. Tidak terkecuali penggunna teknologi informasi yang diterapkan di instansi pemerintah termasuk perum BULOG, Teknologi Informasi (TI) digunakan untuk kemudahan dan kelancaran keperluan masyarakat dan penyebaran informasi.

Perum BULOG merupakan salah satu perusahaan BUMN yang bergerak di bidang logistik beras dan ketahanan pangan, lingkup pekerjaan Perum Bulog Sub Divre Wilayah I Ternate meliputi pengadaan beras bersubsidi yang berasal dari petani, beras bersubsidi disimpan di gudang-gudang Perum Bulog dan akan disalurkan ke masyarakat melalui kecamatan atau kelurahan yang ada di kota ternate untuk membantu dalam kesejahteraan masyarakat yang tidak mampu dan menstabilkan harga beras di pasar (OPK). Perum Bulog Sub Divre Wilayah I Ternate masih menggunakan Microsoft excel sehingga masih kurang ofisien, cepat dan tepat dalam pengolahan data beras. Dengan melihat kekurangan pengolahan data tersebut, maka dibutuhkan sebuah sistem baru yang mampu melakukan pengolahan data secara cepat dan akurat. Salah satu bentuk pengolahan informasi berbasis komputerisasi yaitu sebuah sistem yang memanfaatkan aplikasi web dengan menggunakan pemrograman PHP dan MySQL sebagai basis datanya sehingga memberi kemu-dahan serta kecepatan pengiriman, penyampaian dan penerimaan informasi bagi pengguna.

Berdasarkan latar belakang yang disajikan di atas, menjadi landasan penulis dalam menyusun pemikiran dan konsep untuk penelitian dengan judul "Sistem Informasi Data Beras Pada Kantor Perum Bulog Sub Divre Wilayah I Ternate”.

\section{Rumusan Masalah}

Rumusan masalah dalam penelitian ini adalah bagaimana merancang sebuah sistem aplikasi yang dinamis dan interaktif serta menyajikan data dan informasi secara akurat.

\section{Tujuan Penelitian}

Tujuan dari penelitian ini adalah untuk menyediakan suatu aplikasi informasi agar bisa diketahui dengan mudah dan sebagai media penyimpanan yang tersistematis.

\section{Manfaat Penelitian}

1. Bagi lembaga diharapkan dapat dengan mudah mengakses dan berbagi informasi dimana dan kapan saja.

2. Bagi mahasiswa, penelitian ini akan menambah wawasan dan keterampilan dalam menerapkan ilmu dan pengetahuan yang telah diperoleh.

3. Bagi Program studi, dapat menjadi pembanding antara ilmu manajemen (teori) dengan keadaan yang terjadi dilapangan (praktek), sehingga adanya perkembangan ilmu manajemen informatika dan ditahapkan pada dunia nyata serta menguntungkan berbagai pihak.

\section{Tinjauan Pustaka}

Penelitian yang dilakukan oleh Muhdar Abdurahman; et al, dengan judul Sistem Informasi Akuntansi Arus Kas Pada Kantor Desa Boabneigo Kec. Kao Teluk 
Kabupaten Halmahera Utara,. Tujuan Penelitian ini adalah Merancang System Informasi Akuntansi Pelaporan arus kas pada Kantor Desa Bobaneigo Kec. Kao Teluk, yang mempunyai sasaran terhadap aparat desa agar dapat dengan mudah mengelola keuangan dengan baik sehingga efektif dalam penyajian informasi laoporan arus kas pada setiap bulan

Penelitian oleh Deti dan Mulyono, (2017), Analisis dan perancangan Sistem Informasi Penjualan dan Pemesanan Plywood Berbasiskan Web pada PT. Kumpeh karya lestari jambi. Hasil dari menggunakan situs di jual diharapkan dapat memberikan kemudahan dalam bertransaksi.

penelitian oleh Pratiwi, (2013), Sistem Informasi Penyaluran Beras Raskin Pada Perum Bulog Divre Jateng. Aplikasi dibuat menggunakan Visual Basic 6.0 dan database MySql. Metode pengembangan Sistem yang digunakan yaitu dengan Metode Waterfall

Peneitian yang dilakukan oleh Amien dkk, (2017), yakni Sistem Informasi Pendistribusian Beras Regional Palembang Berbasis Website Hasil rancangan berupa aplikasi yang diharapkan dapat mempermudah pihak Perum Bulog dalam memberikan informasi bagi mitra kerja serta kecamatan dalam pendistribusian beras.

Penelitian oleh Utama, (2011), Sistem Informasi Berbasis Web Jurusan Sistem Informasi Fakultas Ilmu Komputer Universitas Sriwijaya. Dalam membangun sistem ini digunakan Data Flow Diagram (DFD), Context Diagram, Entity Relationship Diagram (ERD) dan Flowchart serta dengan menggunakan bahasa pemrograman PHP dan HYPERTEXT PREPROCESSOR dan MySql sebagai databasenya.

\section{LANDASAN TEORI}

\section{Pengertian Sistem Informasi}

Menurut Pratama 2014 dalam Lase 2017. Menyatakan bahwa sistem adalah sekumpulan prosedur yang saling berkaitan dan saling terhubung untuk melakukan suatu tugas bersama sama. Pengertian sistem yang menekankan pada elemen atau komponennya yaitu sistem adalah kumpulan dari elemen-elemen yang berinteraksi atau berhubungan satu sama lainnya dan bertanggung jawab memproses masukan (input) sehingga menghasilkan keluaran.

Jeperson Hutahaean (2014) Informasi adalah data yang diolah menjadi bentukyang lebih berguna dan lebih berarti bagi penerimanya.Sumber informasi adalah data. Data kenyataan yangmenggambarkan suatu kejadiankejadian dan kesatuannyata. Kejadiankejadian (event) adalah kejadian yangterjadi pada saat tertentu

\section{Entity Relation Diagram (ERD)}

ERD (Entity Relationship Diagram) adalah skema $E R D$ model yang merupakan suatu diagram data untuk menggambarkan hubungan antara satu entitas dengan entitas lain yang mempunyai relasi (hubungan) dengan batasan-batasan yang ada pada masing-masing entitas. Dengan adanya relasi antar database, akan mempermudah dalam mencari, menganalisis, mengorganisasikan, dan melindungi data sejak data dimasukkan dalam database. (Ladjamudin, 2005).

\section{Hypertext Preprocessor (PHP)}

Kadir (2008:2), PHP merupakan singkatan dari Hypertext Preprocessor. Ia merupakan bahasa berbentuk skrip yang ditempatkan dalam server dan diproses diserver. Hasilnyalah yang dikirimkan ke 
klien. Tempat pemakai menggunakan browser. Secara khusus, PHP dirancang untuk membentuk aplikasi web dinamin. Artinya, ia dapat membentuk suatu tampilan berdasarkan permintaan terkini

\section{METODE PENELITIAN}

\section{Metode Pegumpulan Data}

Pertama peneliti melakukan tinjauan terhadap pustaka atau literatur-literatur seperti buku, jurnal, skripsi, atau Ebook baik secara fisik maupun dari internet yang berkaitan dengan judul yang di angkat oleh peneliti. Selanjutnya dari studi literatur yang ada maka di identifikasi permasalahan yang timbul pada studi sebelumnya, selanjutnya penulis membuat perancangan untuk menghasilkan sistem yang lebih relevan dan di implementasikan

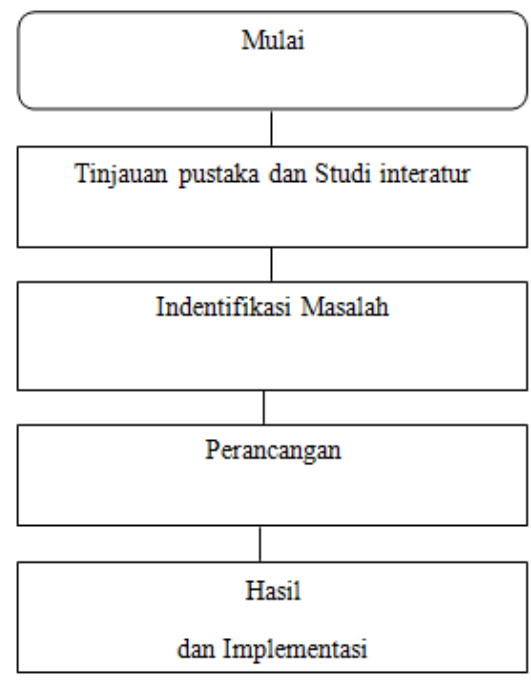

Gambar 1. Alur Penelitian

\section{Pengembangan Sistem}

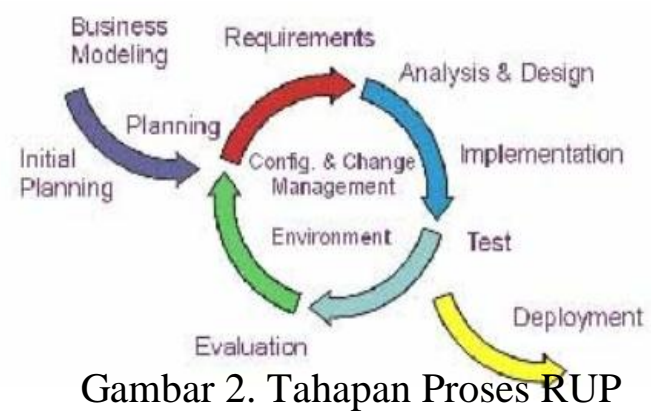

Tahapan tersebut antara lain:
1. Permulaan (Inception) Pada fase ini, penulis melakukan teknik pengumpulan data mengenai sistem yang berjalan di Kantor Perum Bulog Sub Divre Wilayah I Ternate dengan melakukan wawancara kepada pegawai perusahaan. Dilanjutkan dengan kegiatan menganalisis kebutuhan User yang digambarkan dengan menggunakan DFD agar proses yang berjalan dapat diketahui.

2. Perencanaan (Elaboration) Pada fase ini, lebih difokuskan pada perencanaan arsitektur sistem analisis dan desain sistem serta implentasi. yang di mulai dari menspesifikasikan fitur perangkat lunak. Dan dilanjutkan dengan membuat desain sistem yang akan menggambarkan sebuah model sistem untuk menyelesaikan permasalahan yang sedang berjalan dan juga mendeteksi resiko yang mungkin terjadi dari arsitektur yang dibuat. Dalam membuat perancangan sistem penulis menggunakan Software PHP, XАMPP, Boostrap.

3. Konstruksi (Construction) Pada fase ini, penulis membuat kode program pada rancangan sistem yang dibuat pada tahap sebelumnya. Penulis fokus pada pengembangan komponen dan fitur-fitur sistem yang dibutuhkan. Tahap ini lebih pada implementasi dan pengujian sistem yang penulis buat

4. Transisi (Transition) Pada fase ini, lebih pada deployment atau instalasi sistem agar dapat dimengerti oleh User. Penulis menghasilkan produk perangkat lunak yang sudah dapat digunakan oleh perusahaan

\section{ANALISIS DAN PERANCANGAN Analisis Sistem Yang Diusulkan}


Berikut merupakan rancangan sistem yang diusulkan

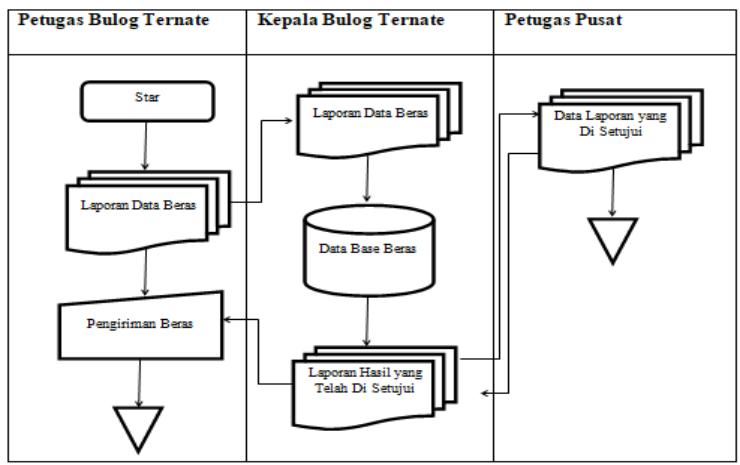

Gambar 3. Sistem yang Diusulkan

\section{Diagram Konteks}

Berikut merupaka gambar rancangan diagram konteks sistem data beras:

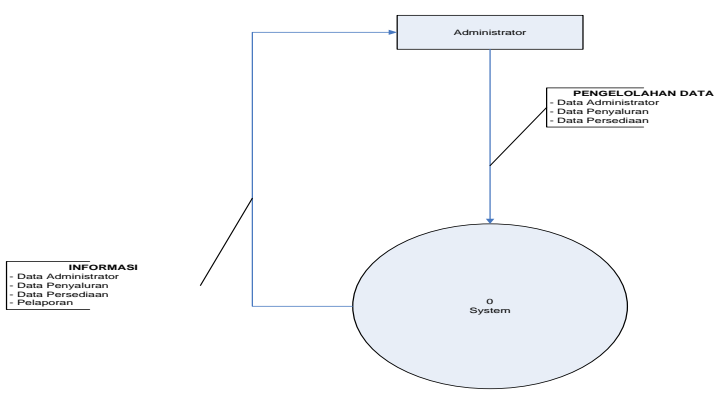

Gambar 4. DFD Level 0

\section{DFD Level 1}

Diagram level 1 merupakan digram tahapan uraian dari digram sebelumnya, berikut merupakan gambar diagram level

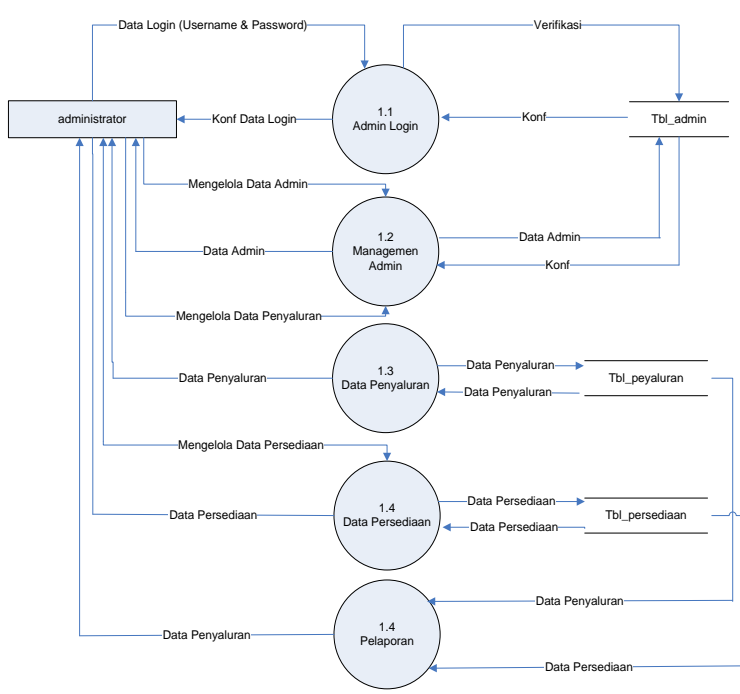

\section{Perancangan Tabel}

Table 1. Berisi Data Penyaluran

\begin{tabular}{|l|l|l|l|l|}
\hline No & $\begin{array}{l}\text { Nama } \\
\text { Field }\end{array}$ & Tipe & Ukuran & Keterangan \\
\hline 1 & $\begin{array}{l}\text { id_ } \\
\text { penyaluran }\end{array}$ & Int & 5 & $\begin{array}{l}\text { ID } \\
\text { Penyaluran }\end{array}$ \\
\hline 2 & $\begin{array}{l}\text { jumlah_ } \\
\text { penyaluran }\end{array}$ & Varchar & 50 & $\begin{array}{l}\text { Jumlah } \\
\text { Penyaluran }\end{array}$ \\
\hline 3 & Bulan & tinyint & 5 & Bulan \\
\hline 4 & Tahun & Int & 5 & Tahun \\
\hline 5 & id_admin & Int & 5 & ID Admin \\
\hline
\end{tabular}

Table 2. Berisi Data Persediaan

\begin{tabular}{|l|l|l|l|l|}
\hline No & $\begin{array}{l}\text { Nama } \\
\text { Field }\end{array}$ & Tipe & Ukuran & Keterangan \\
\hline 1 & $\begin{array}{l}\text { id_ } \\
\text { persediaan }\end{array}$ & Int & 5 & $\begin{array}{l}\text { ID } \\
\text { Persediaan }\end{array}$ \\
\hline 2 & $\begin{array}{l}\text { stok_ } \\
\text { awal }\end{array}$ & Varchar & 50 & Stok Awal \\
\hline 3 & Pemasukan & Varchar & 50 & Pemasukan \\
\hline 4 & Bulan & Tinyint & 5 & Bulan \\
\hline 5 & Tahun & Int & 5 & Tahun \\
\hline 6 & id_admin & Int & 5 & ID Admin \\
\hline
\end{tabular}

\section{Entity Relationship Diagram}

\section{Entity relationship diagram} merupakan diagram relasi antar komponen objek yang terhubung antar relasi, berikut merupaka rancangan $E R D$

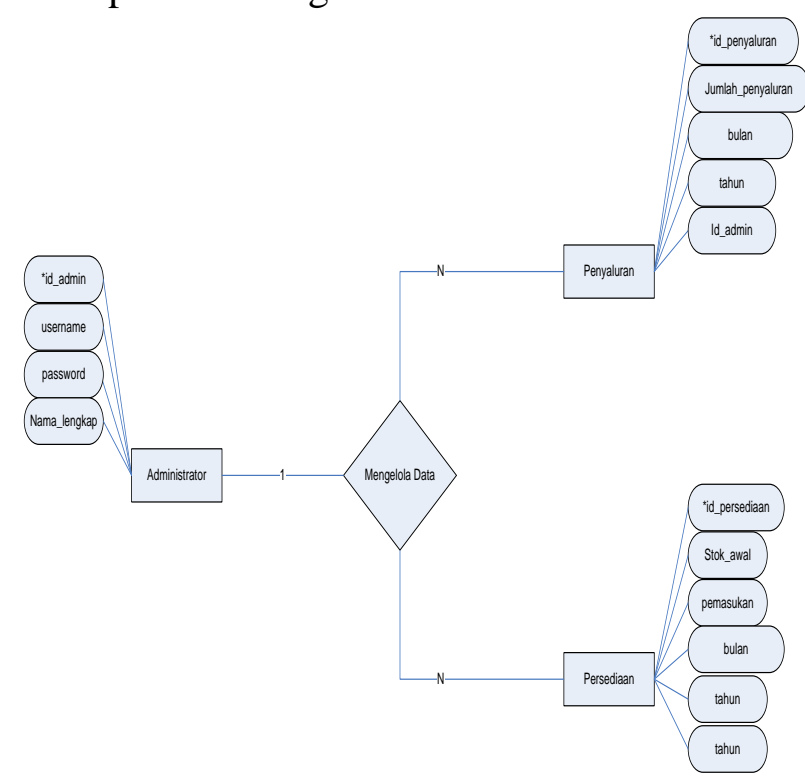

Gambar 6. ERD Notasi

\section{ERD Relasi}




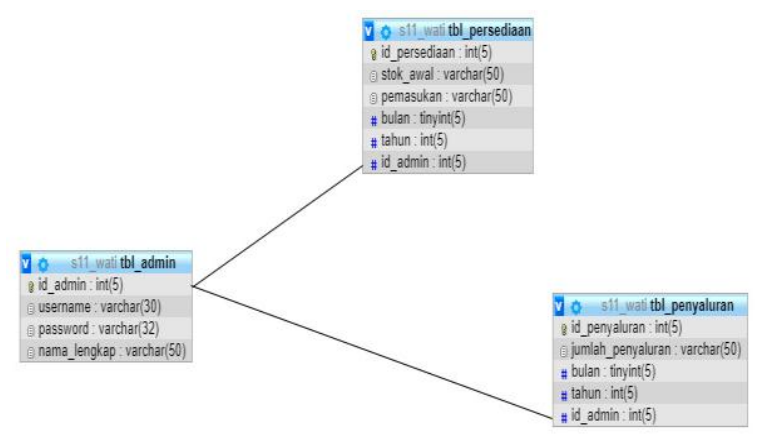

Gambar 7. ERD Relasi

\section{IMPLEMENTASI DAN PEMBAHASAN}

Menurut MT Priyanto; et al, Tahapan ini merupakan hasil dari analisis yang telah di lakukan dengan mengimplementasikan hasil perancangan system

\section{Control Panel}

Tampilan Login Control Panel merupakan Tampilan untuk administrator dapat melakukan proses login. Proses login di haruskan untuk administrator sebelum melakukan pengelolaan data pada sistem.

\section{LOGIN}

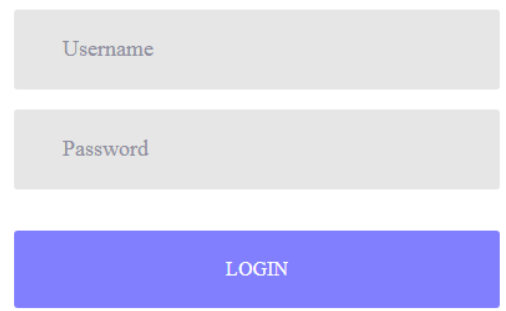

Gambar 8. Tampilan Login

\section{Tampilan Utama Control Panel}

Tampilan utama control panel adalah Tampilan interface awal ketika administrator berhasil melakukan login kedalam system, untuk lebih lengkapnya bisa dilihat pada gambar berikut:

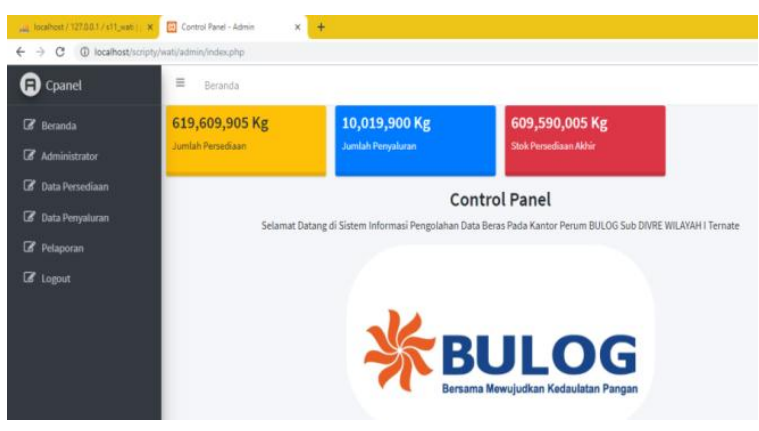

Gambar 9. Control Panel

\section{Tampilan Pengelolaan Administrator}

Tampilan pengelolaan administrator merupakan Tampilan untuk administrator dapat melakukan pengelolaan data administrator.

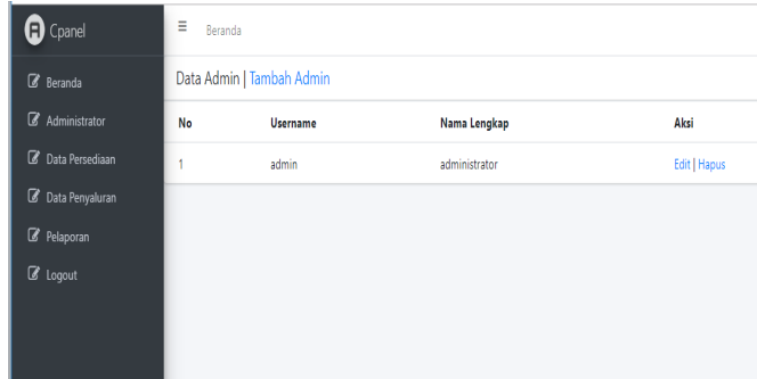

Gambar 10. Tampilan PengolahanAdmin

\section{Tampilan Pengelolaan Penyaluran}

Mmerupakan Tampilan untuk administrator dapat melakukan pengelolaan data penyaluran beras.

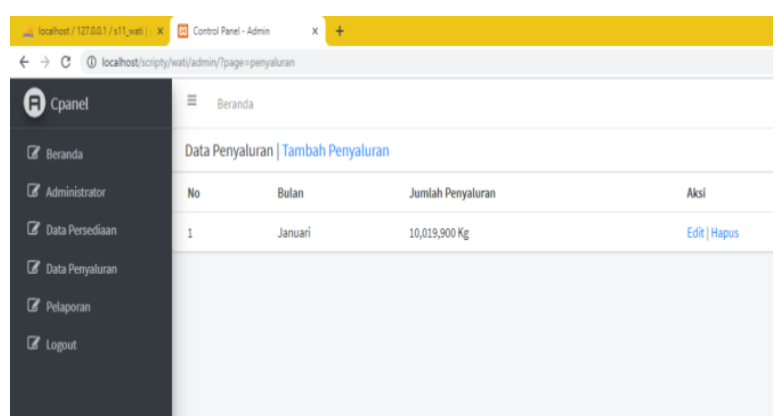

Gambar 11. Tampilan Pengolahan Penyaluran

\section{Tampilan Pengelolaan Persediaan}

Tampilan pengelolaan surat keluar merupakan Tampilan untuk administrator 
dapat melakukan pengelolaan data persediaan

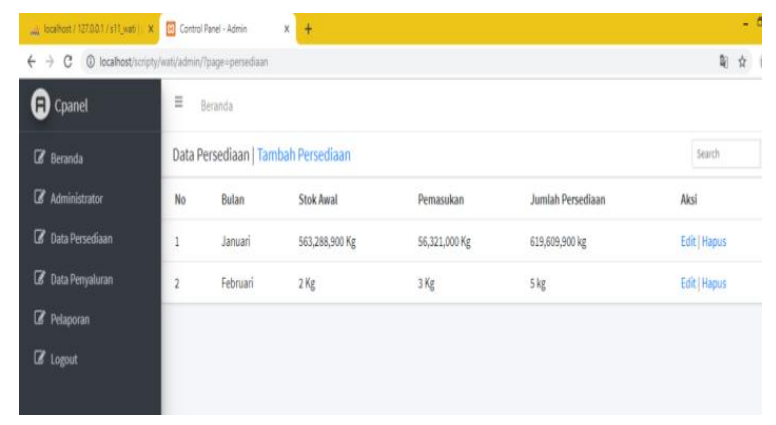

Gambar 12. Tampilan Pengolahan Persediahan

\section{KESIMPULAN}

Berdasarkan hasil, dapat disimpulkan bahwa sistem ini adalah aplikasi yang di rancang sesuai dengan kebutuhan instansi yang dapat mempermuda pengguna untuk dapat di jalankan dengan mudah di Smartphone pengguna karena memiliki kemudahan fitur yang dibuat, dan tentu mengharapkan sebuah Sistem dalam rangka mengetahui kinerja sistem. Maka dari itu, dengan berkembangnya teknologi dan penggunaan teknologi yang terus meningkat, maka aplikasi Sistem Informasi Data Beras Pada Kantor Perum Bulog Sub Divre Wilayah I Ternate Berbasis Web ini sangat dibutuhkan dan membantu bagi pengguna yang ingin melakukan pengelolaan data beras secara online.

\section{Saran}

1. Lebih mempercantik dari segi tampilan agar dapat membuat pengguna semakin nyaman.

2. Dikembangkan lagi dari sisi security website sehingga dapat meminimalisir serangan Hacker yang ingin memanipulasi data transaksi

\section{DAFTAR PUSTAKA}

Abdul Kadir. (2008). Dasar Pemrograman

Web Dinamis Menggunakan PHP. Andi: Yogyakarta

Anna, Indah, Pratiwi, (2013), Sistem Informasi Penyaluran Beras Raskin Pada Perum Bulog Divre Jateng, Fakultas Ilmu Komputer Universitas Dian Nuswantoro.

Abdul Kadir, (1999) Konsep \& Tuntunan Praktis Basis Data, ANDI Yogyakarta,

Al Fatta, Hanif. (2007). Analisis dan Perancangan Sistem Informasi. Yogyakarta : ANDI.

Al-Bahra bin Ladjamudin. (2005). Analisis dan Desain Sistem Informasi. Yogyakarta : Graha Ilmu.

Deti, L., \& Mulyono, H. (2017). Analisis dan Perancangan Sistem Informasi Penjualan dan Pemesanan Plywood Berbasiskan Web pada PT. Kumpeh Karya Lestari Jambi. Jurnal Manajemen Sistem Informasi.

Felisia Lase, (2017). Perancangan Sistem Infomasi Penjualan Pada Fel's Shop Berbasis Web Di Batam. Skripsi, Program Studi Sistem Informasi Sekolah Tinggi Manajemen Informasi Dan Komputer (Stmik) Gici Batam.

Hutahaean, Jeperson, Konsep Sistem Informasi., Ed.1, Cet.1, Yogyakarta: Deepublish, Agustus-(2014).

Indrajani. (2007). Pemrograman Berbasis Objek dengan Bahasa Java. Jakarta: PT.Elex Media Komputindo.

Jogiyanto, Hartono. (2000). Pengenalan Komputer. Yogyakarta : Andi.. 243.

M Abdurahman, A Thalib, A Ambarita, (2019), Sistem Informasi Akuntansi Arus Kas Pada Kantor Desa Boabneigo Kec. Kao Teluk Kabupaten Halmahera Utara, Indonesian Journal on Information 
System, Vol 4 No 2 September, eISSN:2548-6438, p-ISSN:2614-7173

Mas Yusuf Amien (2017), Sistem Informasi Pendistribusian Beras Regional Palembang Berbasis Website Pada Perum Bulog Sumsel, Jurusan Sistem Informasi, Stmik Gi Mdp, Palembang

MT Priyanto, A Samad, SH Hadad, (2019) Sistem Informasi Kependudukan Pada Kantor Lurah Sangaji Berbasis $W e b$, Jurnal Ilmiah ILKOMINFOJurnal Ilmu Komputer dan Informatika Vol 2 No 2 Juli, pp 6067, eISSN: 2621-4970, pISSN: 26214962.

Supriyanto, Aji, (2005) Pengantar Teknologi Informasi, Jakarta: Salemba Infotek,

Yadi Utama, (2011), Sistem Informasi Berbasis Web Jurusan Sistem Informasi, Fakultas Ilmu Komputer Universitas Sriwijaya. 